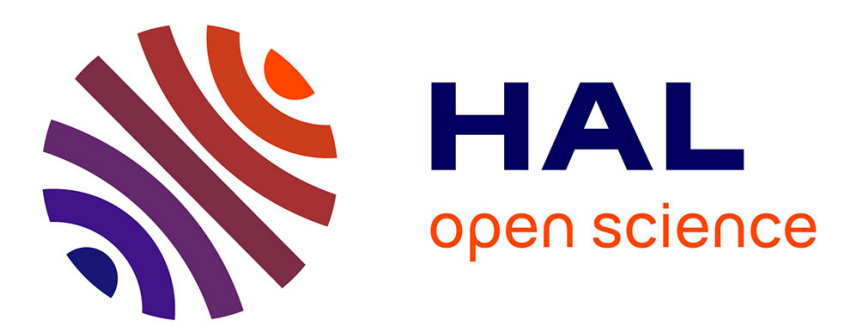

\title{
Influence of Transparent Surface Layer on Effective Thermoreflectance Coefficient of Typical Stacked Electronic Structures
}

\author{
P. L. Komarov, M. G. Burzo, P. E. Raad
}

\section{- To cite this version:}

P. L. Komarov, M. G. Burzo, P. E. Raad. Influence of Transparent Surface Layer on Effective Thermoreflectance Coefficient of Typical Stacked Electronic Structures. THERMINIC 2007, Sep 2007, Budapest, Hungary. pp.126-127. hal-00202547

HAL Id: hal-00202547

https://hal.science/hal-00202547

Submitted on 7 Jan 2008

HAL is a multi-disciplinary open access archive for the deposit and dissemination of scientific research documents, whether they are published or not. The documents may come from teaching and research institutions in France or abroad, or from public or private research centers.
L'archive ouverte pluridisciplinaire HAL, est destinée au dépôt et à la diffusion de documents scientifiques de niveau recherche, publiés ou non, émanant des établissements d'enseignement et de recherche français ou étrangers, des laboratoires publics ou privés. 


\section{Influence of Transparent Surface Layer on Effective Thermoreflectance Coefficient of Typical Stacked Electronic Structures}

Pavel L. KOMAROV, Mihai G. BURZO, and Peter E. RAAD ${ }^{\dagger}$

Nanoscale Electro-Thermal Sciences Laboratory

Department of Mechanical Engineering, Southern Methodist University

Dallas, TX 75275-0337, U.S.A.

\section{EXTENDED ABSTRACT}

It has long been understood that the thermoreflectance coefficient $\left(\mathrm{C}_{\mathrm{TR}}\right)$ varies as a function of light wavelength and material composition. More recent investigations of typical multi-layered electronic devices have uncovered that $\mathrm{C}_{\mathrm{TR}}$ is also influenced dramatically by the presence of a surface passivation (transparent) layer [1]. It is believed that the effective $\mathrm{C}_{\mathrm{TR}}$ is made up of a combination of an intrinsic value and a contribution resulting from the interference of the light beams reflecting from the interfaces of the layers in the light path. To provide an example of this effect, the $\mathrm{C}_{\mathrm{TR}}$ of a poly-silicon heater pad covered by a transparent oxide layer (lighter shaded rectangle in Fig. 1) is shown in Fig. 2 over a wide range of visible light wavelengths. The pattern of the curve is indicative that the intrinsic thermoreflectance response of the polysilicon is modulated by an additional component resulting from the interference of the light reflected from the material interfaces within the light penetration depth.

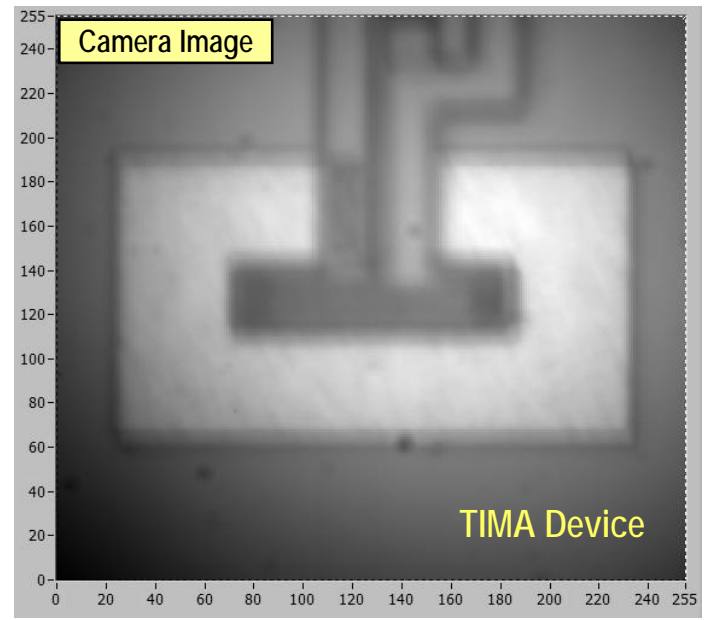

Fig. 1 Poly-Si heater pad

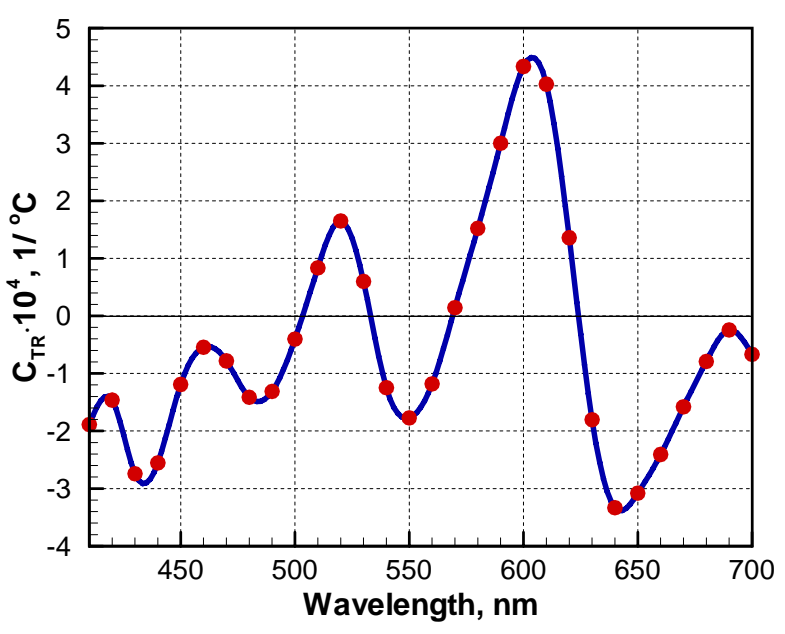

Fig. 2 Thermoreflectance of the poly-Si covered with $\mathrm{SiO}_{2}$ layer

This investigation is targeted at determining the effective $\mathrm{C}_{\mathrm{TR}}$ for composite structures typically found in microelectronic devices; namely, transparent passivation layers covering either semiconductor or metallic materials. The $\mathrm{C}_{\mathrm{TR}}$ measurements are made with a system that the authors built for measuring the $\mathrm{C}_{\mathrm{TR}}$ coefficient at different wavelengths of probing light. A schematic of the system is shown in Fig. 3. The system uses a thermoelectric element to heat up the sample under test with a thermocouple temperature control while illuminating the sample surface at a specific wavelength with a multiwavelength light source. The light from the light source goes through the chopper blades and the fixed

\footnotetext{
† Corresponding Author Email: praad@smu.edu; Tel : 214-768-3866; Fax: 214-768-4998
} 


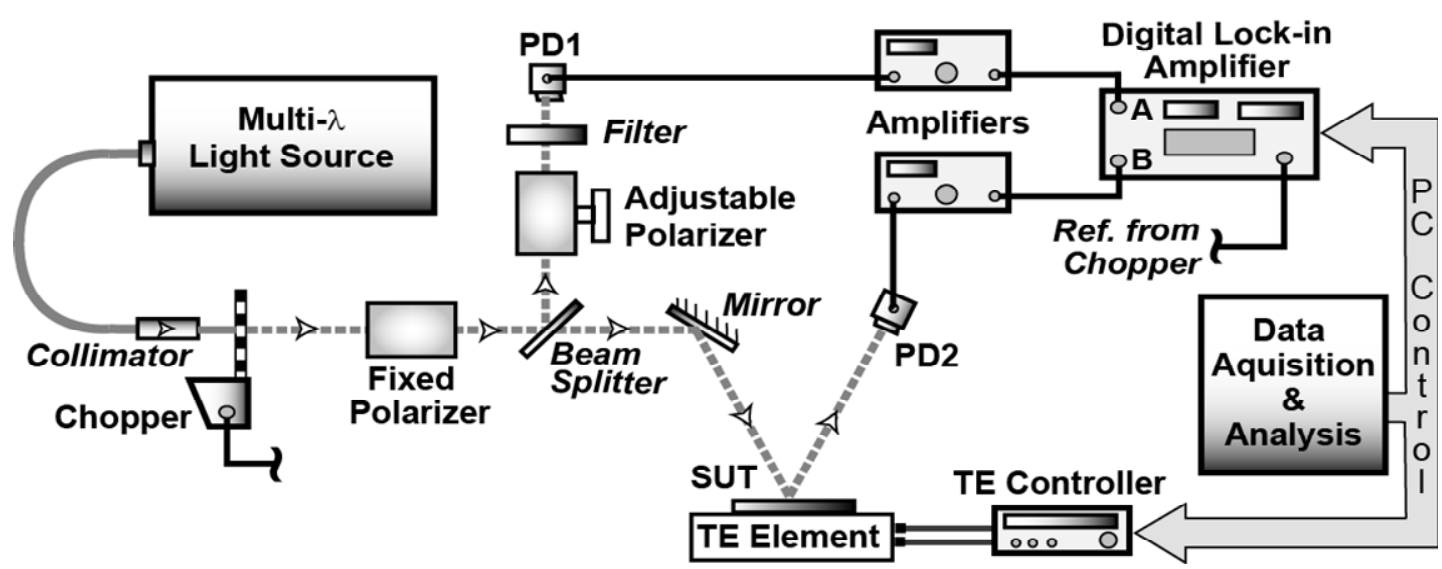

Fig. 3 Schematic of the $C_{T R}$ measurement system

polarizer making the test light linearly polarized. The beam splitter reflects to photodetector PD1 a part of the polarized light, at an intensity controlled by an adjustable polarizer and a filter. The transmitted part of the light falls down to the surface of the sample under test (SUT) and after reflection reaches photodetector PD2. The amplified signals of both photodetectors feed the inputs of a digital lock-in amplifier operating in differential mode. For this scheme to work, it is extremely important that the light intensities traveling through the two PD branches be equal. This light balancing act is achieved by regulating the light intensity in the branch of photodetector PD1 with a computer controlled adjustable polarizer. Once an initial balance is achieved, any small change in the SUT reflectivity can be captured and measured with the lock-in amplifier locked onto the chopper modulation frequency. Test results of the intrinsic value of the $\mathrm{C}_{\mathrm{TR}}$ for gold are in good agreement with those obtained by other investigators (e.g., $4.03 \cdot 10^{-4}$ at $485 \mathrm{~nm}$ ) [2].

The investigation of the influence of a transparent passivation layer on the effective thermoreflectance coefficient of metallic and semiconductor materials is carried out for two materials and two types of passivation layers. The layer of poly-Si or gold is deposited on a Si substrate and covered with a layer of either $\mathrm{SiO}_{2}$ or $\mathrm{Si}_{3} \mathrm{~N}_{4}$. A schematic of the test samples is shown in Fig. 4. To study the light interference effect on the $\mathrm{C}_{\mathrm{TR}}$ value of poly-Si and gold films, the thickness of the passivation layer is varied in the range that envelopes the test wavelength of the light source. The experimental values of the effective $C_{T R}$ are obtained with the intent of correlating them with the intrinsic values of $\mathrm{C}_{\mathrm{TR}}$ for the materials under study (poly-Si and gold) and the thickness and/or material of the transparent passivation layers $\left(\mathrm{SiO}_{2}\right.$ or $\left.\mathrm{Si}_{3} \mathrm{~N}_{4}\right)$. The results and a discussion of the findings will be presented in the full version of the article.

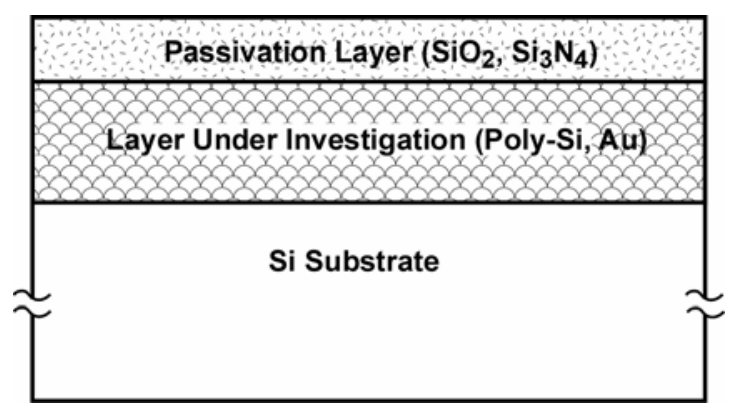

Fig. 4 Schematic of sample under test

[1] G. Tessier, S. Hole, and D. Fournier "Quantitative thermal imaging by synchronous thermoreflectance with optimized illumination wavelengths,” Applied Physics Letters - Vol. 78, No. 16, pp. 2267-2269, 2001

[2] P. Komarov, M. Burzo, and P. Raad “A Thermoreflectance Thermography System for Measuring the Transient Surface Temperature Field of Activated Electronic Devices,” Proceedings of Semiconductor Thermal Measurement and Management (Semi-Therm) Symposium, Dallas, TX, USA, March 2006, pp. 199-203 